\title{
Re-visioning
}

\section{pelvic cape}

through design

Patrycja Zdziarska,

Jeffrey Bardzell \&

Shaowen Bardzell 
Designing for women's health and their bodies is emerging as an agenda in interaction design (Almeida et al. 2016a; Balaam et al. 2017). ${ }^{1}$ Fueled by widely acknowledged disparities in health research among genders, researchers in several fields have focused on women's health to improve our understanding of issues such as menstruation, menopause, and pelvic care. In design fields, including Human-Computer Interaction $(\mathrm{HCl})$, researchers are using design methods to broaden the ways in which the public can participate in health practices. For example, by embracing the hacker and maker movement, scholars have experimented with the hackathon format for enlisting broader involvement in the design of postpartum technologies (D'lgnazio et al. 2016; Hope et al. 2019). They have also leveraged fabrication techniques and emerging technologies to explore intimate wearables (Almeida 2015), Internet of Things (IoT) systems (Fox et al. 2018), and alternative conceptions of trackers (Homewood et al. 2019).

Throughout this work, we see the development of a critical stance towards recognizing and incorporating the concerns and needs of individuals in the design process who have been left out in the past, including but not limited to CIS-gendered women. Specifically, several critiques of health information technologies (ITs) have pointed to the issues surrounding how gendered bodies are framed in the design of health ITs. For one, Epstein et al.'s study of menstrual tracking applications highlights the ways in which these applications fail to account for the full diversity of users and their bodies, as well as changes that bodies undergo across life stages (Epstein et al. 2017). Others have reflected on the relationship between the user and the body in the design of self-tracking tools, proposing design strategies for how designs could account for the changing nature of the body (Homewood 2018). Taking a step further, Homewood has questioned the appropriateness of self-tracking in designing for menopause, raising concerns such as how quantification afforded by self-tracking may result in the privileging of numerical representations above embodied experiences (Homewood 2019). Others have examined the relationship between intimate technologies and intimate data politics, calling attention to their specific logics and politics as well as how they might reinforce a type of intimate body surveillance (Søndergaard / Koefoed Hansen 2016; Søndergaard 2017; Fox et al. 2019).

We argue that feminist scholarship and theory can continue to provide insights to support design in addressing the complex challenges 
of designing for gendered bodies, including CIS-gendered women and LGBTQ+ individuals who might benefit from advances in health concerning female anatomy and related health issues. Feminist scholarship has a long history of engaging with re-visioning work, starting with the re-visioning of the basic assumptions regarding knowledge production that took shape during the women's liberation movement towards the end of the 20th century (Callaway 1981).Scholars of interaction design have built upon feminist insights, proposing the ways in which feminism and design can come together towards social change (S. Bardzell 2010, 2018; Rode 2011). Likewise, Science and Technology Studies (STS) scholars have explored how technologies are or can be feminist by design (Layne et al. 2010). We extend the argument that designers possess the tools and means of not only imagining but also creating alternative worlds and that they are well-positioned to materialize feminist insights.

Drawing on Adrienne Rich's notion of «writing as re-visioning," feminist scholar Helen Callaway considers three senses of re-visioning that characterize feminist research.

[1] «revision» in the standard sense of correcting or completing the record; then [2] «re-vision» as a deliberate critical act to see through the stereotypes that are taken for granted in daily life and deeply embedded in academic tradition; and, finally, [3] «re-vision» in its extended sense as the imaginative power of sighting possibilities and thus helping to bring about what is not (or not yet) visible, a new ordering of human relations. (Callaway 1981: 34; numerical ordering added for clarity)

In providing these senses, Callaway is not offering a prescriptive framework - a recipe for pursuing feminist goals - so much as attempting to characterize how feminists have intervened upon traditional practices of knowledge production in the past. Such interventions have variously operated at the levels of methodology, theory, and intellectual expression, and have collectively foregrounded subjectivity and the epistemic virtues it brings forward: self-awareness and understanding, the gendered character of human experiences, and the impacts of knowledge production on actual bodies. Inspired by Callaway's synthesis work, in this work we use her three senses of re-visioning as a point of departure to ask: how might design revision gendered experiences of health?

Stated more explicitly: the guiding intuition of the present research is that design activism within $\mathrm{HCl}$ and other design disciplines can be read as engaging in one or more of these forms of re-visioning. We therefore engaged in design criticism (J. Bardzell 2009) to develop interpretations of three design cases that are 
each concerned with re-visioning gynecological health. Each of the design cases we consider is either a redesign - a very literal form of re-visioning - or manifests an attempt at imagining and representing different ways of doing gynecological care. Through our critical readings of the design cases, we hope to explore ways that designing (or re-designing) might constitute a material practice of re-visioning in the context of pursuing more equitable gynecological care.

\section{Re-visioning gynecology}

In Public Privates, performance artist Kapsalis provides a critical examination of gynecology through which she develops an account of how pelvic examinations construct female agency, sexuality, and bodies. One implication of her work is that gynecology can be reimagined through a deconstruction of the power structures that sustain the performance of a pelvic exam. She contends that new performances of pelvic examinations will require a different cast of characters with new roles, practices, and tools. Moreover, in these new performances, power will need to be distributed through collaborative engagement between patients and doctors, as well as through new configurations of practices that support self-examination and, along with it, the production of self-knowledge that diverges from a strictly pathological understanding of the female body. She writes:

[The] self-exam can potentially increase a woman's participation in her own care and ensure that she continues to receive care. And, as the many practices, projects, and clinics that arose out of the women's health movement illuminate, the practice of cervical self-exam is about larger issues than simply investigating one's own cervix. It is about imagining a new kind of health care that organizes the female body and its relationship to health and pathology in new ways and therefore reconfigures issues of power and control. (Kapsalis 1997: 170-171)

Following suit, other scholars propose additional ways in which selfexamination could be reclaimed in the context of feminist theories. These scholars consider how second-wave feminism (engagement with the body) can blend with later forms of feminism (intersectional critiques / anti-essentialism).

Davis (2007) confronts the challenge of bridging the gap between two disassociated politics of feminist knowledge: the practical politics of knowledge that runs through women's health activism projects, and the discursive politics of knowledge that is at the center of poststructuralist feminist theory. Davis argues that postmodern feminist theory, «despite its concern for possibilities of resistance and 
transformation in women's bodily practices, $)$ has offered little in terms of «theorizing collective forms of feminist action in and through the body» (Davis 2007: 54). Davis turns to phenomenological perspectives, which «treat women as embodied subjects who think, act, and know through their bodies» (Davis 2007: 57). For Davis, phenomenology offers a theory of agency that links experiences, the body, and action «that is not abstract but practical. Agency is always embedded in women's everyday interpretive activities» (Davis 2007: 60). Such an approach avoids the pitfalls of second-wave feminism (i.e. essentialism) and third-wave feminism (i.e. a commitment to discourse that is ultimately disembodying).

Davis is not alone in her effort to re-emphasize the role of the body in feminist thought. Gender and health researchers Kuhlmann and Babitsch (2002) make a similar move, proposing uto bring the material body back into feminist theory and to further new concepts that take the living and changing body into account» (Kuhlmann/Babitsch 2002: 433). In their case, highlighting the body is not a philosophical commitment so much as a pragmatic one, given their interest in linking feminism to women's health. More recently, Fahs (2015) has argued that third-wave feminism itself provides new intellectual resources to understand the body: «because of the tools we have been given from the third wave to more meaningfully theorize and understand intersecting identities and intersecting oppressions, we are now in a position to better address the body as corporeal while also thinking deeply about intersectionality and social identities» (Fahs 2015: 396-397).

If the centrality of the body is needed for an emancipatory practice focused on female body parts and functions - as women's health is frequently positioned - then the body should be equally central to design. Designs constitute much of the physical ecologies in which our lives unfold, and practical intention underlies how they get made, why they were acquired, and how they are used. In short, design reflects all of Davis' key elements of a feminist phenomenology: agen$c y$, as an outcome of embodied, meaningful, and practical engagements with the world. If gendered health experiences - such as the pelvic exam - are to have new distributions of power, casts of characters, performances, and engagements, as Kapsalis hopes, that is, if they are to be revised, then it seems that design is a material practice upon which any such re-visions hinge. In such a light, we consider three design projects that, in diverse ways, all do such work: Labella, Yona Care, and GynePunk. 
We examine the following three design cases, each of which proposes a re-visioning of gynecology in the contemporary moment through advances in technology and design. These design cases were selected because they express worthwhile design aspirations grounded in diverse sets of commitments, ranging from Interaction Design's technointerventionist approach of Labella (an interactive self-discovery tool), to the Experience Design approach of Yona Care (re-designed experience of pelvic exams), and the transfeminist approach of the GynePunks (critical making and hacking of a collection of tools and practices for self-care). Thus, each case offers a contrasting view of how re-visioning can take place, allowing us to map the space of possibility and collectively expand the technological and social imagination of possible future designs.

\section{Labella}

Labella (Almeida et al. 2016b, 2016c) is a technology probe about vaginal self-examination. The design includes a smart phone app and specially marked underwear that allows people to examine vagina anatomy virtually. It was developed in part as a response to research showing that only half of women in a recent survey could correctly locate the vagina on a diagram of the female reproductive system (Almeida 2016). As a technology probe (Hutchison et al. 2003), the intention behind Labella was not so much that it be offered on the commercial market, but rather to explore an ill-defined design space and to understand how potential users would respond to such a device were it available. Though it is not available for commercial purchase and is not on any app stores, its creators have published two scientific articles about it, and it has also been written up in popular media, including The Conversation (Almeida 2016) and Glamour (Weiss 2016)

More specifically, Labella (Fig. 8.1) is an augmented reality pelvic fitness system consisting of a mobile phone application and a pair of augmented underwear that guides users through situated embodied self-discovery (Almeida et al. 2016b, 2016c). While all interactions using Labella take place with the underwear on, the system invites users to "look down there» by pointing the camera of the phone at the visual marker on the accompanying underwear. The app then presents illustrations and 3D models of female anatomy, in addition to simulations of its physiology, to help users locate and understand the functioning of their pelvic muscles (Fig. 8.2). After this learning occurs, the app engages users in a series of timed pelvic exercises, where 

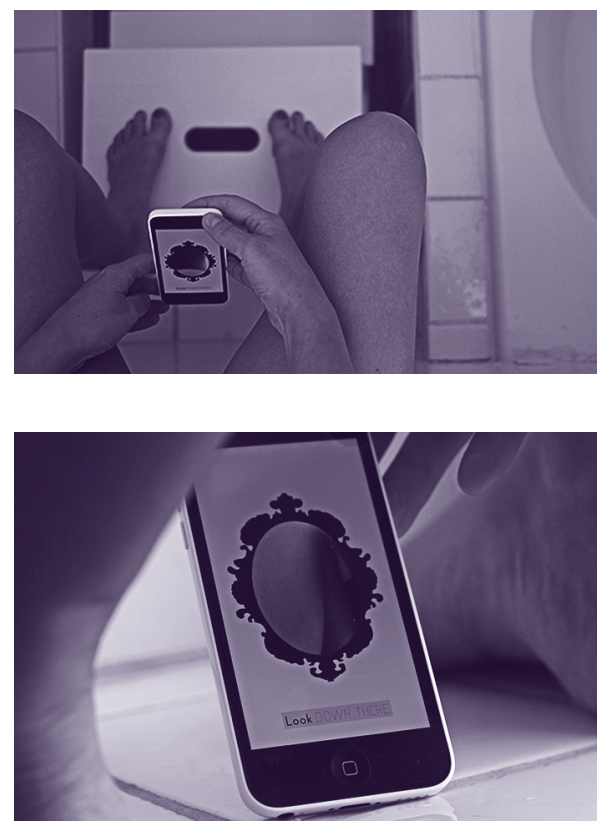

Fig. 8.1 Images of Labella, 2016. Photo credits: Ko-Le Chen. Illustration/ collage: Teresa Almeida. Used with permission. they respond in a physical manner by contracting or releasing their pelvic floor muscles to exercise their pelvic floors. Vaginal examinations are often uncomfortable experiences, whether performed by a medical professional or oneself. Reasons range from the power dynamics of being subjected to an objectifying gaze, in the context of medical practice, to taboos and a shroud of mystery about genitals, female in particular (Kapsalis 1997). Labella's use of the vocabularies of contemporary interaction design - apps, cameras, 3D models, and virtual representations - explores a space in which pelvic health tools might be redesigned for broader appeal. The design team characterizes its intentions with Labella as follows:

We illustrate how Labella can contribute towards an enhanced self-learning experience for women, through which they can gain awareness of the intimate parts of their body. We show how designing for aw/kward learning experiences, onbody interactions and humour can break the taboo related to learning about hidden parts of the body, which in turn can enable better self-care or care of others. (Almeida et al. 2016a: 1811)

Several features of Labella are worth elaborating. Given the link between self-examination and pelvic health, Labella is addressing a serious societal issue, and it views education - where people learn about their vaginas - as a tactic to improve health. Obviously, such education is already abundantly available in books, on the Internet, and so forth (e.g. Herbenick/Schick 2011). But Labella makes several moves that books and online browser searches typically do not. One is that Labella is interactive; one does not read about an examination, but rather one performs a simulation of one. Another, related, is that Labella utilizes its user's body beyond eyes and hands (screen and keyboard). Users must point Labella at the underwear covering their pelvic areas for it to function correctly. Even though Labella neither sees nor directly represents the user's actual vulva, nonetheless the user interacts with those parts of the body as though it did. In doing so, it separates the kinesiology of a self-examination from the visual study by performing the former while merely virtualizing the latter. Labella also encourages exploration in part through ambiguity. It uses 

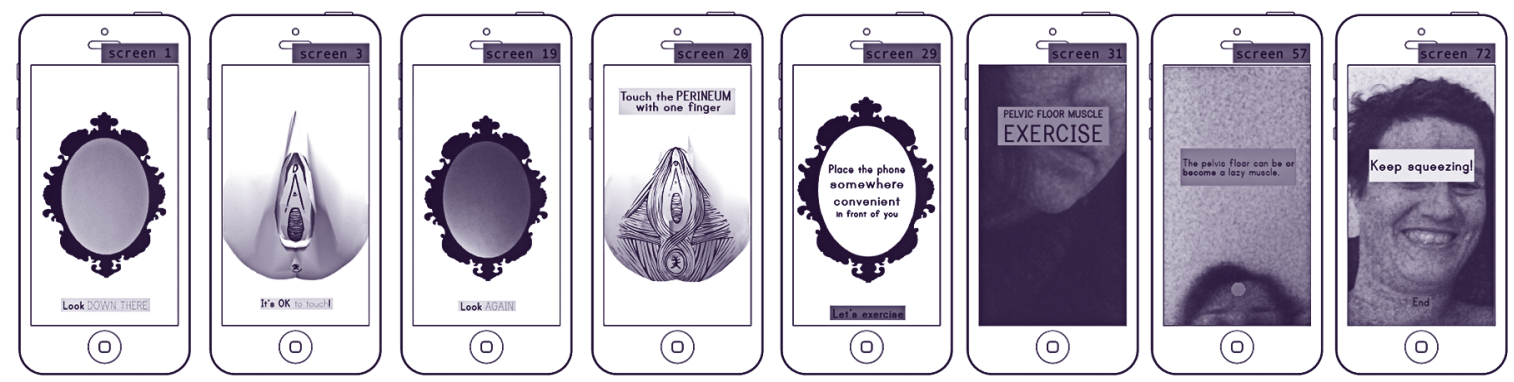

Fig. 8.2 Labella: a selection of screen designs, 2016. Screen design: Teresa Almeida. Used with permission.

a combination of encouraging prompts («it's okay!») and directives («look») before turning to deliberately ambiguous language (e.g. "touch the Perineum with one finger») that does not specify whether to touch the Perineum on the app or on the body itself.

Labella proposes an alternative to book- and web-based presentations of anatomy and how to conduct pelvic exams by leveraging the language of interaction design and patterns of consumer behavior. In doing so, it positions itself as an educational intervention and helps to make visible and normalize certain bodily practices and resulting knowledge. It also attempts to imagine what technologies might need to look like if they are to be actually used. For example, the authors in a previous work report the challenges of getting users to comply with pelvic exercise prescriptions despite them being recommended by doctors.

Much of the critical work of this design project has been made possible on account of two interrelated factors: Labella has a fully materialized form (i.e. it is not a description of a product, but an actual product), and it has been offered as a technology probe, rather than a consumer product. We discuss each of these points in turn. Concerning its materialization, we make several observations. Many health-related devices on the market today embody one of the following two aesthetics: either they are medical-looking devices strong on ergonomics and weak on visual appeal, or they are sporty consumer electronic products along the lines of the FitBit. The Labella's use of the ornate frame, informal language, and humor is disarming, a crucial quality for a design intended to help people work through an awkward experience.

And because it demands a physical performance from the user as part of its interaction model, it scaffolds, like training wheels on a bike, an unfamiliar physical activity by easing people into it. One aspect of the design that is and should be humorless is its graphic depiction of female anatomy itself. The visual representations of the 
That it has been positioned as a tech-

nology probe is also significant. Technology probes are described in the literature above all as research tools - that is, their purpose is to support inquiry: "the social science goal of understanding the needs and desires of users in a real-world setting, the engineering goal of field-testing the technology, and the design goal of inspiring users and researchers to think about new technologies»

(Hutchison et al. 2003: 17).

Labella should not be interpreted as though it were a marketready consumer device in the way that Glamour magazine did in its write-up, when it asked: «Not really sure why you'd need this? Yeah, neither were wey (Weiss 2016). It is instead interesting because Labella shows how the act of designing can be used to explore design problem domains in a materialized way, embodying and performing the very possibility of intervention into social problems (in this case, unnecessary problems concerning pelvic health) shaped in part by regressive ideologies and practices.

Labella thus re-visions pelvic exams in the following ways. The pelvic exam is a self-exam, unmediated by a medical professional; it is the individual who gazes, both subject of knowledge and object of inquiry. This knowing subject and object of inquiry are of the same body, and the performance of the inquiry itself is materialized and embodied. The exam is inquiry-driven and playful, an exploration that unfolds at its own pace, scaffolded as needed to overcome aw/kwardness, and unapologetically frank in its sight, touch, and knowledge. The result is to restore knowledge and experiences of the pelvic area to the individual whose body it is a part of - as their birthright.

\section{Yona Care}

Yona Care is an «early-stage experience design concept that reimagines the pelvic exam» developed by a group of designers at Frog Design. ${ }^{2}$ The concept consists of a redesigned speculum (the medical tool used for the exam), an app that provides a guided experience of the pelvic exam, as well as a set of guidelines for making aesthetic adjustments to examination rooms. Yona Care is situated as a form of health advocacy, aiming to reimagine the experiential and affective dimensions of pelvic exams, mainly the ways in which they cause stress, fear, discomfort, and embarrassment. The designers created it partly in response to their ow/n experiences of having a pelvic exam, which triggered a set of questions about why it was taboo to talk about 
While the new speculum is still a workin-progress, the ideas supporting it are presented as a design proposal through illustrations, a mini manifesto, and a set of design principles on the Yona Care website. There, the reimagined speculum consists of upgrades to its form, feel, and sound, where the designers focused on addressing the qualities that make it threatening. The form, for example, is reimagined through the lens of improved ergonomics drawn from the sex toy industry, which has pioneered the development of body-grade silicone that could also be autoclaved (sanitized). The designers have added a digital experience delivered through an app that is envisioned to be used before and after the exam. For example, prior to an exam, the app offers a guided meditation to relieve stress as well as the option to shop for accessories such as socks to further upgrade the experience. This brief shopping excursion doubles as a donation drive. The funds from these purchases are redirected towards improving access to gynecological care for others. The designers express their intentions as follows:

We drew inspiration from a lot of places, but focused on experiences that emphasize comfort and relaxation, such as the patient-centered approach that midwives take. We were also influenced by mindfulness and meditation and even meditated before our work session. Our goal was to focus on keeping you relaxed because the more mentally calm you are, the less physically tense you are as well. This makes for a less anxietyinducing and less painful experience. ${ }^{3}$

While Yona Care appears in many ways to be a redesign of the speculum, it is important to note that the designers frame this as an experience problem, not as a device problem. That is, the designers consider the speculum not only through a functionalist lens (i.e. supporting a medical professional's examination practice) or an ergonomic lens (i.e. how the speculum fits with human anatomy), but through experience-driven and activist lenses. Specifically, they sought to create conditions where examinees would be relaxed, helping to alleviate both emotional shame and physical pain, and where patients would feel empowered to intervene upon the medical establishment and bring about change.

This reframing expands the question of re-designing the speculum to the entire exam ecology, which includes not just the physical tools but also the stakeholders (doctors, patients, family, friends, health professionals), as well as the environment (the actual exam room) - much as Kapsalis (1997) proposed. The designers turn to 
design methodologies, rather than feminist theory, to pursue this work: user-centered and patient-centered design. They even experimentally developed a design method for building empathy, in which they showed the speculum to three CIS-gendered men, and then asked them to read first-person accounts of visits to the gynecologist. They found that the participants were unfamiliar with the particularities of gynecological exams and were surprised by the form factors of the speculum. They appeared uncomfortable reading the accounts and one participant even expressed feeling violated in a metaphorical way.

Finally, the designers further expand the scope of their problem framing beyond the pelvic exam itself, for example by taking their advocacy to social media. In other words, educating people, dispelling myths, and motivating activism all contribute to improving experiences of pelvic exams. They use social media to build a following in support of this movement, elevating the issue into a fully legitimate and recognizable social movement. Pursuing these goals led to graphic design work as well as a social manifesto on the website, hoping to produce a powerful story that could attract attention. All of which contribute to making this idea easy to share on social media.

As the designers expand the scope of the problem frame, starting with the device and their own immediate experiences of pelvic exams and gradually broadening in the ways we have shown, they became sensitized to more dimensions of these experiences. For example, they initially framed the project in terms of women's health, but over time they realized that they were excluding the experiences of people within the LGBTQ+ community. Thus, what was initially called the «Women's Health Concept Project» was renamed simply as "Yona Care" and they stopped using words such as woman or she, instead using «health for people with vaginas» (Freethink 2019). In other words, the designers' unfolding sensitization in turn revealed more opportunities for intervention, cumulatively adding up to a more systemic awareness of the ideological, material, and practical infrastructures on which such experiences depend. Their design activities made some of this hidden infrastructure visible and open to change and critique, giving the designers - and their audiences - a clearer sense of how the system unfolds and how people and designs reproduce those infrastructures. The project has also had a significant public footprint. For example, the designers initiated an AMA (Ask Me Anything) on Reddit.com to address questions about the design. The discussion led to debates about the need for the exams in the first place, the frequency of exams, and finally whether exams should be paired up with access to birth control. People also chimed in to share their stories and exchange knowledge about the particularities of gynecology. In addition, they offered ideas for how the exam could be 
4 https://www.reddit.com/r/TwoXChromo somes/comments/7hpo87/were_hailey_ sahana_rachel_and_fran_designers_and. further reworked such as through the involvement of doulas, the choice to self-insert the speculum, as well as the use of a trauma-informed approach to care. ${ }^{4}$

As further evidence of public impact,

Yona Care has received a Design Award (Driven X Design New York Design Award 2017). Moreover, in recent years, media attention around these issues has resurfaced in part because of designs like Yona Care, which is just one of the many attempts at redesign. In these accounts (e.g. Blei 2018; Fonder 2017; Breen 2017; Pardes 2017), Yona Care is often contextualized in relation to those previous attempts, the broader history of gynecology, and discussions of the difficulty of disrupting medical practices. Thus, Yona Care can also be viewed as keeping these conversations alive and part of ongoing discussions about regressive practices that often recede into the periphery.

A more critical interpreter would no doubt hasten to observe that all this attention that Yona Care has won for reimagining pelvic exams has also been attention won for Frog Design. A cynic might even go so far as to say that the real purpose of Yona Care is to generate industry buzz that raises reputation better than traditional advertising. We do not take such an extreme view, but it seems fair to wonder whether Frog Design would have invested so much energy into Yona Care had it not provided industry buzz. Either way, we must note the inextricability of Yona Care's altruistic and corporate reputationbuilding effects. Yona Care raises an interesting point moving forward. Feminist scholars like Kapsalis call for a disruption in pelvic exams, and Silicon Valley design firms often derive economic and social capital for their ability to be disruptive. Yet disruptive in Silicon Valley parlance is tied to capitalist notions of innovation and economic development and it is broadly disconnected from political activism. Can design projects such as Yona Care introduce more political consciousness into capitalist disruption, or will capitalism reclaim and dilute activism for its own purposes? It is possible today to read Yona Care either way.

\section{GynePunks}

The GynePunks are an autonomous gynecology lab within the Hackteria network, ${ }^{5}$ a biohacking collective of artists, researchers, makers, and scientists that emerged in 2009. They formed within a postindustrial eco colony called Calafou in Catalonia and characterize themselves as transfeminists (Koyama 2003), queer hackers, vagina hackers, and cyborg witches, who share a concern for re-claiming the body from patriarchal and capitalist grips. Their work responds to the history 
gynecology that is rooted in self-research carried out by gender-binaryresisting hackers. It also responds to the general lack of access to affordable medical care that characterizes many parts of the world, as well as a lack of knowledge on the part of the public in being able to carry out and interpret basic self-exams or medical tests. As such, it attempts to recreate a gynecology that can stand autonomously apart from the mainstream system through the combined use of low-cost tools and equipment, existing scientific and medical knowledge that has been hacked and translated into practical use, and traditional knowledge gained from holistic health practices.

Importantly, their design and hacking efforts extend beyond tools and practices (of which they offer a plethora) into hacking the ways in which body parts have been socially constructed. For example, by framing vaginas as something that needs to be hacked, they suggest that the vagina may not only be subject to alterations and physical hacking, but also a hacking that is more akin to re-claiming one's personal rights to the vagina, which can be as basic as the capacity to learn about it to understand it. They express this in the following way:

We understand our body also as a technology to be hacked, from the established ideas of gender and sex, to exploring the capacity to start researching ourselves, to find our own ideas and technologies, to help us be free, autonomous and independent from the system. (Paula Pin, GynePunk, interview in Bierend 2015)

Specifically, the GynePunks have developed a full low-cost biolab for processing and analyzing bodily fluids such as blood and urine, as well as a repository of information on alternative self-care practices that they have translated into an accessible form. They have also inspired the design of an open source 3D printable speculum by Gaudi Labs (2015). These tools are developed as a means of democratizing knowledge about self-care. Much of their work pushes the boundaries of what can be a DIY (do-it-yourself) or DIT (do-ittogether) practice, often exposing the irony of contemporary medical advances, where scientifically straightforward procedures such as urine analysis continue to be expensive at the doctor's office, whereas they could be performed using simple tools and techniques that are both affordable and economical.

The GynePunks provide the following description of their intentions on the THF! Convergence Report (2014: 2-3), reproduced below, including all the original capitalization and punctuation: 
Gynepunk is about engaging in a radical change of perspective about medical technologies, and the so-called «professional» and medical institutions. Gynepunk is an extreme and accurate gesture to detach our bodies from the compulsive dependency of the fossil structures of the hegemonic health system machine. Gynepunk's objective is to enable the emergence of DIY-DIT accessible diagnosis labs and techniques in extreme experimentation spaces, down on the rocks or in elevators if it is necessary. It is about having these possibilities in a situated stable place or/and in nomadic mobile labs to be able to perform as much as WE WANT, in an intensive way: smears, fluid analysis, biopsy, PAPs, synthesize hormones at will, blood tests, urinalysis, HIV tests, pain relief, or whatever WE NEED. It is about hacking and building our own ultrasound, endoscope or ecography devices in a low-cost way. All this experimentation is made in complementarity with herbs and natural knowledges, oral traditions, underground recipes, seeking with hunger to generate a plethora of DIY lubricants, anti-contraceptives, open doula domains, savage caring of any visceral hands-on technologies, such as menstrual extraction, all elevated to the maximum potential of common learning and radical self-body-power ...!

Gynepunk is based on scientific methodologies and disciplines and relies on the knowledge that comes through the experience of each body and from ancestral body wisdom; that is also why documentation and memory under any form is essential! ANY format: visual treasures, sound mines, microscopic riddles, biologic cabinets, microbiologic growing centers, online seedbanks, fluids archives, fanzine (paper sms), oral decoding chorus, self-voodoo healing rituals. Like those, gynepunks will ferment and mutate going fast forward to an explosive and expansive movement towards radical experiments, collective strong confidence, to build our-body politics; something that is vital to share and spread in infinite pandemoniums. Nobody can burn US! NO ONE! The witches NOW have the flames// (THF! Convergence Report 2014: 2-3)

We recognize that DIY gynecology is not a novel idea. Gynecology has always crossed paths with some sort of DIY from ancient practices of alternative medicine to the self-help practices of the women's health movement in the 1970s (Boston Women's Health Book Collective 1973). The GynePunks are a continuation of these historical precedents as they also try to establish a more salient relationship to gynecology's history; through their practices they offer a direct critique but also a materialized model of what an alternative might look like and how it 
could be pursued. At the same time, they make full use of recent developments in hacker culture, using the vocabularies and ideologies of hacking as well as recent technological developments, e.g. digital fabrication. Through their work, they also clarify the troubling relationships between social constructions of the vagina and who has rights to it, and the consequences of those relationships as they play out in reality. For example, the GynePunks lament that getting even the most basic information about one's body requires being subjected to long lines at waiting rooms, tests whose results are only interpretable by doctors, as well as surveys and questions that request the disclosure of private or sensitive information. All of these highlight the unequal power relationships that might deny one's right to self-care.

That GynePunks position their work as founded in scientific methodology is significant. Their rejection of how contemporary science has been institutionalized in conventional medicine - seen as politically regressive and disempowering - does not generalize to a rejection of science itself. Instead, scientific ways of knowing are mixed in with other epistemologies such as traditional knowledge, experimental art practices, and critical technical practices like hacking to realize a different form of self-care. Like other contemporary science movements, such as citizen science, GynePunk seeks to democratize science - anyone can do it. But in contrast to at least some forms of citizen science, GynePunk is not an educational onramp to traditional science, but rather a survival tactic. In other words, the end goal is not to participate in science, but rather to use science to engage in acts of self-care that have hitherto been made invisible by medical science.

Various press outlets such as Vice (Bierend 2015), Makery (Chardronnet 2015), and 3D Printing Industry (Koslow 2015) have written about the GynePunks, and the reporters often wonder about the practical aspects of this work, such as whether it is safe. To some, DIY cervical tests might seem dubious and questionable, but to others they may be an appealing alternative. What this suggests is that while all of these practices theoretically exist out there and could be democratized, the infrastructure to bring them together in a culturally appropriate way is lacking. We should read the GynePunks as experimenting with and prototyping the type of infrastructural work necessary for the establishment of an alternative, which is inclusive to not just physical places, tools, and practices, but also cultural consciousness and awareness to support these alternatives. The hacking consists of not just hacking devices and tools, but also the broader culture, so as to be more inclusive to different conceptions 
of hacking and different forms of participation from people of all genders (THF! Convergence Report 2014; Fox et al. 2015).

The GynePunks show how design, making, and fabrication might be used as a medium for exploring and prototyping alternative models We read it as a form of critical making (Ratto 2011), where the purpose of experimenting and making is in materializing alternative knowledge practices and forms, even if the materializations fail to meet commercial standards of technical feasibility and/or economic viability. Within the report, they also position this as Liberating Technology:

Liberating technologies are rooted in libre/free culture and its participants aim to embrace, protect and advance it. ... Liberation technologies for us mean taking back the control of the internet, infrastructure, algorithms, inscribing new values in code, among others. (THF! Convergence Report 2014: 9)

The ethos driving GynePunk is a belief that technology can participate in an emancipatory project. However, this is not mere technological determinism: even liberating technologies do not by themselves emancipate. Instead, the GynePunks also make important ideological moves. For example, they embrace a non-binary conception of gender and the body - rejecting mainstream binaries of female/male - to envision a more fluid account of the range of gender possibilities. The gender binary is so ingrained in our understanding of reality that it is difficult to imagine an alternative, and GynePunk's materializations from such an ideological world go far to support such imaginings. The GynePunks also demonstrate through their critical making that self-care can be done in far from pristine environments (which can be a reality for many in different parts of the world where access to basic sanitation is limited), or that it can be self-taught given the right resources and support such as tools and technologies that make selfcare efficient, accessible, and economically viable.

\section{Re-visioning through design}

Thus far we have considered three design cases that each offer particular attempts at re-visioning gynecological care. It is important to remember that we do not interpret these design cases as solutions, but rather as illustrations of possibilities, each undertaken from different positions of what is understood to be desirable. We hoped that by critically engaging these cases we might develop an understanding of how re-visioning work may proceed through design.

The very concept of re-visioning implies not only the intellectual concepts of change and intervention, but also some materialized or embodied phenomenon that we see, and hence can potentially re-see. 
As a practice, designing - even in its most commercialized forms is often positioned as a practice that converts existing situations into preferred ones through acts of material making. Yet what designers make goes far beyond physical artifacts; designers also shape practices, experiences, services, and relationships. Further, designers seldom invent out of whole cloth entirely new products; instead, they are informed by and make use of existing meanings and forms already available, much as Yona Care redesigned the speculum. This chapter has explored ways in which design - always already a practice of redesign - might also become a practice of re-visioning in the three senses that Calloway uses the term: to correct or complete the record, to see beyond stereotypes, and to spot possibilities by engaging one's imaginative powers.

All three design cases reimagine both practices and ideologies associated with vaginal care. Labella reimagines self-examination - the intimate relationship one has with one's own body, unmediated by others. It uses play to decouple self-examination from cultural connotations of shame and taboo, while encouraging a more contextualized and embodied self-examination. Labella suggests that redesign might proceed through a new linking that is less concerned with formal practices of gynecological care tied to the epistemologies of the medical profession and more concerned with personal body literacy and comfort that is made possible through tools that facilitate self-examination. It re-visions in the sense of correcting and completing an individual's relationship with their vagina. Yona Care embraces a similar ethos but takes it into the exam room, advancing the view that pelvic exams should pay greater attention to the affective and experiential qualities of such exams, pursuing these objectives in part by redesigning the speculum as a tactic of materializing these concerns. In its starting point of rejecting the speculum as given, it broke past assumptions of what a pelvic exam is supposed to be, re-visioning the exam as an engaging and comfortable experience. Even more radically, the GynePunks propose an autonomous gynecology - one that takes medical practitioners out of the exam and empowers individuals themselves. Doing so demands significant ideological shifts regarding gender, bodies, and self-care. In this view, gynecology is not only positioned as a means of reclaiming rights to one's body through increased competency with self-care practices, but also as a means of providing an alternative to those who are denied access to proper care in the first place. The GynePunks invoke far-reaching imaginative power to sight new possibilities, even if doing so has short-term, pragmatic difficulties.

One question that is often foregrounded in discussions of health activism is the question of who benefits from interventionist efforts 
and who continues to be left behind. For example, we might wonder what difference a redesigned pelvic examination makes if those who are in most need of these services do not have a means of obtaining the most basic forms of care. In this sense, we might ask what type of re-visioning work is really required to address these health disparities. However, that is not to say that re-visioning cannot proceed through processes that continually re-shape existing social relations as a way of continually opening up possibilities for new design. Instead, what we have gained from these design cases is an illustration of what different starting points for this re-visioning might look like if they were to be pursued within existing infrastructures and contemporary sensibilities

Taken together, these design cases demonstrate, each in their own way, the type of work that designers might engage in to further pursue this agenda. Particularly, we infer from these cases that if future designs hope to address health disparities, they must do so not only through more equitable design of tools, or configurations of roles, but also through a more direct engagement with those who are adversely affected. This includes those who do not have access to proper care, but also those who are unaccounted for in design processes because they diverge from what is considered to be the model user, where the user might be a model based on conformity to cultural stereotypes of feminine hygiene, heteronormative conceptions of womanhood, or medicalized expectations embedded in the very idea of care itself. Challenging all of these manifestations of misogyny requires discursive, ideological, and yet also material interventions. One way to re-vision is quite literally to redesign. 
Almeida, Teresa (2015): «Designing Intimate Wearables to Promote Preventative Health Care Practices.» In: Adjunct Proceedings of the 2015 ACM International Joint Conference on Pervasive and Ubiquitous Computing and Proceedings of the 2015 ACM International Symposium on Wearable Computers, ACM, pp. 659-662.

Almeida, Teresa (2016): «There's a New Way to Look at Your Vagina That Might Just Save Your Life.» The Conversation, May 16, 2016, https://theconversation.com/ heres-a-new-way-to-look-at-your-vagina-it-might-justsave-your-life-59021.

Almeida, Teresa / Comber, Rob / Balaam, Madeline (2016a): « $\mathrm{HCl}$ and Intimate Care as an Agenda for Change in Women's Health.»l In: Proceedings of the 2016 CHI Conference on Human Factors in Computing Systems, ACM, pp. 2599-2611.

Almeida, Teresa / Comber, Rob / Wood, Gavin/Saraf, Dean / Balaam, Madeline (2016b): «On Looking at the Vagina through Labella.» In: Proceedings of the 2016 CHI Conference on Human Factors in Computing Systems, ACM, pp. 1810-1821.

Almeida, Teresa / Wood, Gavin / Comber, Rob / Balaam, Madeline (2016c): «Interactivity: Looking at the Vagina through Labella.») In: Proceedings of the 2016 CHI Conference Extended Abstracts on Human Factors in Computing Systems, ACM, pp. 3635-3638.

Balaam, Madeline/Hansen, Lone Koefoed/D'Ignazio, Catherine / Simpson, Emma / Almeida, Teresa / Kuznetsov, Stacey / Catt, Mike / Søndergaard, Marie L. J. (2017): «Hacking Women's Health.» In: Proceedings of the 2017 CHI Conference Extended Abstracts on Human Factors in Computing Systems, ACM, pp. 476-483.

Bardzell, Jeffrey (2009): «Interaction Criticism and Aesthetics.ll In: Proceedings of the SIGCHI Conference on Human Factors in Computing Systems, ACM, pp. 2357-2366.

Bardzell, Shaowen (2010): «Feminist HCl: Taking Stock and Outlining an Agenda for Design.») In: Proceedings of the SIGCHI Conference on Human Factors in Computing Systems, ACM, pp. 1301-1310.
Bardzell, Shaowen (2018): «Utopias of Participation:

Feminism, Design, and the Futures.» ACM Transactions on Computer-Human Interaction 25/1, Article 6, pp. 1-24.

Bierend, Doug (2015): «Meet the GynePunks Pushing the Boundaries of DIY Gynecology.» Vice, August 21, 2015, https://motherboard.vice.com/en_us/article/qkvyjw/ meet-the-gynepunks-pushing-the-boundaries-of-diygynecology.

Blei, Daniela (2018): «Women are Reinventing the LongDespised Speculum. The Gynecological Apparatus, Designed by Men, has a Sordid History. An Object Lesson.» The Atlantic, March 8, 2018, https://www.theatlantic.com/technology/archive/ 2018/03/women-redesigning-speculum/555167.

Boston Women's Health Book Collective (1973): Our Bodies, Ourselves: A Book by and for Women, New York: Simon and Schuster.

Callaway, Helen (1981): «Women's Perspectives: Research as Re-vision.»l Convergence 14/4, pp. 34-43.

Breen, Claire (2017): «Women Behind Speculum Redesign Say We Need Gynecological Tools Designed by People with Vaginas: Envisioning a Future in W/hich Gynecology Doesn'† Have a ¿Fatherı..) The Lily, October 12, 2017, https://www.thelily.com/women-behind-speculum-re design-say-we-need-gynecological-tools-designed-bypeople-with-vaginas.

Chardronnet, Ewen (2015): «GynePunk, the Cyborg Witches of DIY Gynecology.» Makery, June 30, 2015, http://www.makery.info/en/2015/06/30/gynepunk-lessorcieres-cyborg-de-la-gynecologie-diy.

Davis, Kathy (2007): «Reclaiming Women's Bodies: Colonialist Trope or Critical Epistemology?» Sociological Review 55/1, pp. 50-64.

D'Ignazio, Catherine / Hope, Alexis / Michelson, Becky / Churchill, Robyn / Zuckerman, Ethan (2016): «A Feminist $\mathrm{HCl}$ Approach to Designing Postpartum Technologies: When I First Saw a Breast Pump I Was Wondering if It Was a Joke.»I In: Proceedings of the 2016 CHI Conference on Human Factors in Computing Systems, ACM, pp. 2612-2622.

\section{References}


Fox, Sarah E./ Howell, Noura / Wong, Richmond Y./Spektor, Franchesca (2019): «Vivewell: Speculating Near-Future Menstrual Tracking through Current Data Practices.l) In: Proceedings of the 2019 on Designing Interactive Systems Conference, ACM, pp. 541-552.

Driven X Design (2017): «2017 New York Design Awards,» https://drivenxdesign.com/NYC17/project.as p?ID=16399.

Epstein, Daniel A. / Lee, Nicole B. / Kang, Jennifer H. / Agapie, Elena / Schroeder, Jessica / Pina, Laura R. / Fogarty, James / Kientz, Julie A. / Munson, Sean (2017): «Examining Menstrual Tracking to Inform the Design of Personal Informatics Tools.ı In: Proceedings of the 2017 CHI Conference on Human Factors in Computing Systems, ACM, pp. 6876-6888.

Fahs, Breanne (2015): «The Body in Revolt: The Impact and Legacy of Second Wave Corporeal Embodiment.» Journal of Social Issues 71/2, pp. 386-401.

Fonder, Allison (2017): «Frog's «Yona) Project Reimagines the Awkward Gynecology Visit Experience: And a Redesign of the Speculum, a Medical Instrument That Hasn't Been Refined in Years.) Core77, October 10, 2017, https://www.core77.com/posts/69384/frogs-YonaProject-Reimagines-the-Awkward-Gynecology-VisitExperience.

Fox, Sarah E. / Ulgado, Rachel Rose / Rosner, Daniela K. (2015): «Hacking Culture, Not Devices: Access and Recognition in Feminist Hackerspaces.nI In: Proceedings of the 18th ACM conference on Computer Supported Cooperative Work \& Social Computing, ACM, pp. 56-68.

Fox, Sarah E. / Silva Rafael M. L. / Rosner, Daniela K. (2018): «Beyond the Prototype: Maintenance, Collective Responsibility, and Public loT.»I In: Proceedings of the 2018 Designing Interactive Systems Conference, ACM, pp. 21-32.
Freethink (2019): «This Team is Redesigning the Vaginal Speculum to Improve the Experience for Everyone with a Vagina,ll October 9, 2019, https://www.freethink.com/ videos/vaginal-speculum-pelvic-exam-tool.

Gaudi Labs (2015): «GynePunk Speculum.» Thingiverse, June 5, 2015, https://www.thingiverse.com/ thing:865593.

Herbenick, Debby/Schick, Vanessa (2011): Read My Lips: A Complete Guide to the Vagina and Vulva, Lanham, MD: Rowman \& Littlefield Publishers.

Homewood, Sarah (2018): «Designing for the Changing Body: A Feminist Exploration of Self-Tracking Technologies.l) In: Extended Abstracts of the 2018 CHI Conference on Human Factors in Computing Systems, ACM. Homewood, Sarah (2019): «Inaction as a Design Decision: Reflections on Not Designing Self-Tracking Tools for Menopause.» In: Extended Abstracts of the 2019 CHI Conference on Human Factors in Computing Systems, ACM.

Homewood, Sarah / Bewley, Harvey / Boer, Laurens (2019): "Ovum: Designing for Fertility Tracking as a Shared and Domestic Experience.» In: Proceedings of the 2019 on Designing Interactive Systems Conference, ACM, pp. 553-565.

Hope, Alexis / D'Ignazio, Catherine / Hoy, Josephine / Michelson, Rebecca/Roberts, Jennifer/Krontiris, Kate/Zuckerman, Ethan (2019): «Hackathons as Participatory Design: Iterating Feminist Utopias.» In: Proceedings of the 2019 CHI Conference on Human Factors in Computing Systems, ACM. 
Hutchinson, Hilary/Mackay, Wendy/Westerlund, Bo / Bederson, Benjamin B. / Druin, Allison / Plaisant, Catherine / Beaudouin-Lafon, Michel / Coversy, Stéphane / Evans, Helen / Hansen, Heiko / Roussel, Nicolas / Eiderbäck, Björn (2003): «Technology Probes: Inspiring Design for and with Families.» In: Proceedings of the SIGCHI Conference on Human Factors in Computing Systems, ACM, pp. 17-24.

Kapsalis, Terri (1997): Public Privates: Performing Gynecology from Both Ends of the Speculum, Durham, NC: Duke University Press.

Koslow, Tyler (2015): «Decolonizing the Female Body with the Bio-hacking of GynePunk.» 3D Printing Industry, August 25, 2015, https://3dprintingindustry.com/news/ decolonizing-the-female-body-with-the-bio-hacking-ofgynepunk-56324.

Koyama, Emi (2003): «The Transfeminist Manifesto.» In: Rory Dicker / Alison Piepmeier (eds.), Catching a Wave: Reclaiming Feminism for the 21st Century, Boston: Northeastern University Press, pp. 244-259.

Kuhlmann, Ellen / Babitsch, Birgit (2002): «Bodies, health, gender: bridging feminist theories and women's health.») Women's Studies International Forum 25/4, pp. 433-442.

Layne, Linda L. / Vostral, Sharra Louise / Boyer, Kate (2010): Feminist Technology. Vol. 4. Urbana, IL: University of Illinois Press.

Pardes, Arielle (2017): «The Speculum Finally Gets a Modern Redesign.») Wired, October 5, 2017, https://www.wired.com/story/the-speculum-finallygets-a-modern-redesign.

Ratto, Matt (2011): «Critical Making: Conceptual and Material Studies in Technology and Social Life.» The Information Society 27/4, pp. 252-260.

Rode, Jennifer A. (2011): «A Theoretical Agenda for Feminist $\mathrm{HCl} . »$ Interacting with Computers 23/5, pp. 393-400.
Søndergaard, Marie L. J. (2017): «Intimate Design: Designing Intimacy as a Critical-Feminist Practice.» In: Proceedings of the $2017 \mathrm{CHI}$ Conference Extended Abstracts on Human Factors in Computing Systems, ACM, pp. 320-325.

Søndergaard, Marie L. J. / Hansen, Lone Koefoed (2016): «PeriodShare: A Bloody Design Fiction.» In: Proceedings of the 9th Nordic Conference on Human-Computer Interaction, ACM.

TransHackFeminist (THF!) Convergence Report (2014): Calafou, Catalonia, August 4-11, https://transhackfeminist.noblogs.org/post/2015/ 01/25/a-transhackfeminist-thf-convergence-report.

Weiss, Suzannah (2016): «So, There's an App That'll Spy on Your Vagina for You...» Glamour, May 19, 2016, https://www.glamour.com/story/labella-app-vagina. 
